\title{
An Analysis of Primary School Students' Conceptual Knowledge of Geometric Solids
}

\section{Lütfi İNCİKABI*}

Received: 02 Novamber 2012

\author{
Çiğdem KILIÇ**
}

Accepted: 18 June 2013

ABSTRACT: This study aims to analyze and interpret primary school students' conceptual knowledge of geometric solids. For this reason, a diagnosis test consisting of three questions which measure primary school students' conceptual knowledge of cube, square prism and rectangular prism. Participants of the study consisted of 272 sixth graders among whom 12 were selected for interviews. Data obtained were analyzed both quantatively and qualitatively. According to the results, very few students were able to name solids and also their characteristics. Furthermore, it was determined that students have some misconceptions of geometric concepts. Generally, students either assimilated three-dimensional geometric concepts to two-dimensiomal geometric shapes or declared real names of pictures. Moreover, some students did not provide any response or explanation to the questions.

Keywords: geometric solids, conceptual knowledge, primary school.

\section{Extended Abstract}

Purpose and Significance: It is emphasized that learning mathematics requires acquisition of the knowledge of basic concepts and skills (Ministry of National Education [MoNE], 2009) and concepts in mathematics are very important since mathematics itself is a language (Altun, 2008). Concept is a form of knowledge that represents common characteristics of different objects and cases that have meaning in mind (Ülgen, 2001). When developmental levels of students considered, mathematical concepts are quite difficult to be perceived directly since the nature of mathematics is quite abstract. In order to do effective mathematics instruction, it is necessary for students to have a complete understanding of mathematical concepts. The primary school mathematics curriculum in Turkey includes many geometric concepts including geometric shapes and solids. In the curriculum, it is expected that students are able to name a cube, square and rectangular prisms and their characteristics. Basically, review of the relevant literature revealed that students have some misconceptions related to geometric concepts. Some studies also indicated that students have difficulties and misconceptions of geometric shapes. However, there has been a gap in the literature in terms of studies which concentrate on primary school students' conceptual knowledge of geometric solids. The purpose of the current study is to explore primary school students' conceptual knowledge of cube, square prism and rectangular prism. It also aims to determine their misconceptions, if any, of those concepts.

\footnotetext{
*Assist. Prof. Dr., Kastamonu University, Kastamonu, Turkey, lutfiincikabi@yahoo.com ***Assist. Prof. Dr., Mersin University, Mersin, Turkey, ckilic6@gmail.com
} 
Method: This is a case study. Data were collected through a diagnosis test consisting of three questions which also include the pictures of a cube, a square prism and a rectangular prism. The diagnosis test was developed to analyze primary school students' conceptual knowledge of cube, square prism and rectangular prism. Students were asked to name those solids and their characteristics. A total of 272 students participated in the study. Interviews were conducted with 12 students who provided different responses. Data were analyzed both quantatively and qualitatively. First of all, students' responses were coded according to a codebook. Frequency and percentage tables were provided and interpreted. The interview data were analyzed by means of the content analysis technique. The inter-coder agreement rate was calculated as $90 \%$.

Results: Almost all $83 \%$ of students were able to name the cube. However, only $7 \%$ could explain all characteristics of the cube. $23 \%$ of students could determine some characteristics of the cube. The analysis of students' responses to the characteristics of the cube revealed that $9 \%$ of students could name face characteristics of the cube, $15 \%$ vertice and 5\% edge characteristics correctly. In general, students could name the cube correctly, but only a few could name it and its characteristics. Students had some trouble with naming the cube and its characteristics. $6 \%$ of students named the object asked as a square, $4 \%$ of them called it with its real name (e.g. box) and $6 \%$ of students did not provide any response. About half (48\%) of students could name the square prism. Only $6 \%$ of students were able to name the characteristics of the square prism and $14 \%$ of them could name the characteristics of the square prism partially. The analysis of students' responses to the characteristics of the square prism revealed that $7 \%$ of students named face characteristics of the square prism, $12 \%$ vertice and $2 \%$ edge characteristics correctly. Half of students could name the square prism correctly, but very few could name the prism and its characteristics. Students had some trouble with naming the square prism and its characteristics. 30\% of students assimilated the object asked to a geometric shape such as a square, $4 \%$ called its real name such as a box and $14 \%$ of students did not say anything about the square prism. About half $(47 \%)$ of students could name the rectangular prism. Only 6\% of students could name the characteristics of the rectangular prism, and $13 \%$ of students could name the characteristics of the rectangular prism partially. In terms of the characteristics of a rectangular prism, $6 \%$ of students could name face characteristics of the rectangular prism, $9 \%$ of them vertice and only $1 \%$ edge characteristics correctly. Half of students could name the rectangular prism correctly, but very few could name the prism and its characteristics. Students had some trouble with naming the rectangular prism and its characteristics. $35 \%$ of students assimilated the object asked to a geometric shape, $6 \%$ of them called its real name (e.g. box) and $12 \%$ of students did not say anything about rectangular prism.

Discussion and Conclusions: According to the results of the study, it can be concluded that very few of students could name the solids and their characteristics. Furthermore, it 
was determined that students have some misconceptions of geometric concepts. Generally, students either assimilated solids to geometric shapes or declared real names of the pictures. Moreover, some students did not provide any responses to the questions. 


\title{
İlköğretim Öğrencilerinin Geometrik Cisimlerle İlgili Kavram Bilgilerinin Analizi
}

\author{
Lütfi İNCİKABI ${ }^{*}$
}

\author{
Çiğdem KILIÇ**
}

Makale Gönderme Tarihi: 02 Kasım 2012

Makale Kabul Tarihi: 18 Haziran 2013

\begin{abstract}
ÖZET: Bu çalışma ile ilköğretim öğrencilerinin bazı geometrik cisimlere yönelik kavram bilgilerini analiz etmek ve yorumlamak amaçlanmıştır. Bu amaç doğrutusunda öğrencilere üç sorudan oluşan teşhis testi uygulanmıştır. Bu teşhis testi, ilköğretim öğrencilerinin küp, kare ve dikdörtgenler prizması kavramlarına yönelik kavramsal bilgilerini analiz etmek için hazırlanmıştır. Çalışmaya toplam 272 ilköğretim öğrencisi katılmış olup 12 öğrenci ile de görüşmeler gerçekleştirilmiştir. Araştırmadan elde edilen verilerin analizinde hem nicel hem nitel veri analiz yöntemleri kullanılmıştır. Araştırmadan elde edilen sonuçlara bakıldığında, ilköğretim öğrencilerinin çok azının hem geometrik cisimlerin isimlerini hem özelliklerini doğru bildikleri belirlenmiştir. Bunun yanı sıra, öğrencilerin küp, kare ve dikdörtgenler prizmasına yönelik kavram yanılgılarının da olduğu belirlenmiştir. Öğrenciler kendilerine verilen resimlere bakarak prizmaları, geometrik şekillere benzetmişler ya da resimlerin gerçek isimlerini belirtmişlerdir. Ayrıca, bu çalışmada yanıt verememe durumu da gözlenmiştir.
\end{abstract}

Anahtar Sözcükler: geometrik cisim, kavram bilgisi, ilköğretim

\section{Giriş}

Matematiği öğrenmek için temel kavram ve becerilerin kazanılmasının gerekli olduğu (Milli Eğitim Bakanlığı [MEB], 2009) ve kavramların, matematiğin kendisi bir dil olduğu için, önemli olduğu vurgulanmaktadır (Altun, 2008). Kavram, insan zihninde anlamlanan, farklı obje ve olguların değişebilen ortak özelliklerini temsil eden bir bilgi formu ya da yapısıdır, bir değişkendir; bir sözcükle ifade edilir (Ülgen, 2001). Paylaştıkları ortak özellikler nedeniyle aynı küme, sınıf ya da kategori içinde yer alan örnekler bir kavram oluşturur (Şimşek, 2006). Kavramlar, bir çeşit zihinsel tutkal gibidirler, geçmiş deneyimlerimizle şimdiki deneyimlerimizi birbirine bağlarlar (Murphy, 2002). Kavramların dayandığı özelliklerin ortak ve değişken olmak üzere ikiye ayrıldığı görülmektedir. Örneğin; üçgen kavramını ele alırsak, üçgen kavramını tanımlayan ortak özellikler, üçgenin üç kenarlı kapalı bir şekil olması, iç açılarının ölçülerinin toplamının 180 derece olmasıdır. Değişken özelliklere örnek olarak da bazı üçgenlerin üç kenarının, bazılarının da iki kenarının aynı uzunlukta olduğu verilebilir (Şimşek, 2006). Matematiğin yapısında tanımsız kavramlar, tanımlar, aksiyomlar ve teoremler gibi temel elemanlar vardır (Küçük \& Demir, 2009).

Matematikle ilgili kavramların, doğası gereği, soyut nitelikli ve çocukların gelişim düzeyleri dikkate alındığında doğrudan algılanmalarının oldukça zor olduğu belirtilmektedir (MEB, 2009). Soyut yapısı düşünüldüğünde matematiksel kavramların tam anlamıyla kavranılmasında, öğrenilmesinde yaşanan güçlüklerin, matematik öğrenimi ve öğretiminin zor olarak algılanmasının kaynağını teşkil eden nedenler arasında gösterilebileceği üzerine vurgu yapılmaktadır (Kar, Çiltaş, \& Iş̧ı, 2011). Bu nedenle, matematikle ilgili kavramlar, somut ve sonlu yaşam modellerinden yola çıkılarak ele alınmıştır. Programda kavramsal öğrenme ile işlem becerilerine de önem

\footnotetext{
*Yrd. Doç. Dr., Kastamonu Üniversitesi, Eğitim Fakültesi, lutfiincikabi@yahoo.com

** Yrd. Doç. Dr., Mersin Üniversitesi, Eğitim Fakültesi, ckilic6@gmail.com
} 
verilmektedir. Kavramsal yaklaşım, matematikle ilgili bilgilerin kavramsal temellerinin oluşturulmasına daha çok zaman ayırmayı ve böylece kavramsal ve işlemsel bilgi ve beceriler arasında ilişkiler kurmayı gerektirmektedir. Programda matematiksel kavramların geliştirilmesi gerektiği yönünde vurgu yapıldığı görülmektedir (MEB, 2009).

İlköğretim matematik derslerinde öğrenciler çeşitli matematiksel kavramlarla karşılaşmaktadırlar. Bunlardan bazıları geometride yer alan kavramlarla ilgilidir ve matematik dersi öğretim programlarında önemli bir yer tutmaktadır. Bu öneme rağmen Türkiye'deki öğrencilerin geometri konularındaki başarısızlığı, ulusal SBS (Seviye Belirleme Sınavı ve LYS (Lisans Yerleştirme Sınavı) ve uluslararası TIMSS (Trends in International Mathematics ve Science Study) ve PISA (Program for International Student Assessment) gibi sınavlarda belirgin olmaktadır. İlköğretim düzeyindeki öğrencilerin bazı geometrik kavramlarda yanılgıya düşmelerinin (Doğan, Özkan, Çakır, Baysal, \& Gün, 2012; Küçük \& Demir, 2009; Yenilmez \& Yaşa, 2008;) geometri konusunda başarısız olmalarına neden olduğu düşünülmektedir.

İlköğretim matematik dersi öğretim programı incelendiğinde, geometrik şekillerin yanı sıra, geometrik cisimlere de yer verildiği görülmektedir. Cisim denince, ilköğretim düzeyinde, akla küp, dikdörtgenler prizması, silindir, küre, dörtyüzlü, koni ve piramidin geldiği ve bunların ilköğretim yıllarında tanındığı belirtilmektedir (Altun, 1999; MEB, 2009). Programda küp, kare ve dikdörtgenler prizması ile birinci sınıfta karşılaşan öğrenciler, ikinci, üçüncü ve beşinci sınıflarda da bu prizmalarla ilgili birtakım etkinlikler yapmaktadırlar. Öğrenci beşinci sınıfa geldiğinde ise öğrencilerden geometrik cisimlerin isimlerini belirterek özelliklerini açıklamaları beklenmektedir (MEB, 2009).

Öğrencilerin katı cisimleri öğrenmeleri üzerine yapılan çalışmalar, genellikle öğrencilerin üç boyutlu katı cisimlerle iki boyutlu temsilleri arasındaki bağlantıları kurabilme ve katı cisimler hakkında muhakeme yapabilme becerilerine odaklanmıştır. Birinci kısma odaklanan araştırmalarda genellikle katı cisimlerin çizimleri (Lehrer, Jenkins, \& Osana, 1998), açınımlarının çizimi (Potari \& Spiliotopoulou, 1992), açınımları tanıma (Bourgeois, 1986), açınımları açıklama (Lawrie, Pegg, \& Gutiérrez, 2000) ve açınımları inşa etme (Despina, Leikin, \& Silver, 1999) incelenmiştir. Katı cisimler hakkında muhakeme yapma becerileri ile ilgili çalışmalarda, genellikle küplerle oluşturulan diğer yapıların incelenmesi (Battista \& Clements, 1998; Ben-Chaim, Lappan, \& Houang, 1985), öğrencilerin katı cisimler hakkındaki muhakemelerinin Van Hiele seviyeleri bakımından incelenmesi (Gutiérrez, Jaime, \& Fortuny, 1991), öğrencilerin uzaysal (spatial) becerilerinin değerlendirilmesi (Saads \& Davis, 1997), bilgisayar yazılımlarının veya teknolojilerinin katı cisimlerin öğretimine entegre edilmesi (Markopoulos \& Potari, 2003; McClintock, Jiang, \& July, 2002) amaçlanmıştır.

Etkili bir matematik öğretimi yapabilmek için o konulara ilişkin kavramların öğrenciler tarafından tam olarak kazanılması gerektiği belirtilmektedir (Küçük \& Demir, 2009). İlköğretim öğrencilerinin matematik eğitimi kapsamında yer alan bazı 
kavramlara yönelik kavram yanılgısı yaşadıkları görülmektedir (Dağlı \& Peker, 2012; Doğan, Özkan, Çakır, Baysal, \& Gün, 2012; Kaplan, İşleyen, \& Öztürk, 2011; Pesen, 2008; Yenilmez \& Yaşa, 2008; Yılmaz \& Yenilmez, 2008). Kavram yanılgıları ile ilgili ilköğretim matematik dersleri kapsamında yapılan çalışmalara bakıldığında, kesir (Pesen, 2008), oran ve orantı (Kaplan ve diğerleri, 2011), yamuk (Doğan ve diğerleri, 2012), ondalık sayılar (Yılmaz \& Yenilmez, 2008), 1şın, doğru ve doğru parçası (Yenilmez \& Yaşa, 2008) konularında öğrencilerin sorunlar yaşadıkları görülmüştür. Geometride yer alan kavramlara yönelik kavram yanılgıları ile ilgili çalışmalarda, daha çok öğrencilerin geometrik şekillerle (Doğan ve diğerleri, 2012) ilgili kavram yanılgıları üzerine durulmuştur. Doğan ve diğerleri (2012), ilköğretim düzeyinde öğrencilerin geometri ile ilgili pek çok kavramı yanlış algılamalarının ya da eksik öğrenmelerinin daha sonra birçok sorunun yaşanmasına neden olduğunu ifade etmişlerdir. Kaynaklarda "kavram yanılgısı" ile "hata" kavramının sıkça bir arada kullanılması, bazen bu iki kavramın birbiriyle karıştırılmasına sebep verebilmektedir. Hata (error), kavram yanılgısının bir sonucudur. Yani, kavram yanılgısına sahip bir öğrenci bunun sonucu olarak problem çözümünde veya belli konularda hatalı yaklaşımlar kullanabilmekte ve hatalı sonuçlara ulaşabilmektedir. Kavram yanılgısı, bir hata veya bilgi eksikliğinden yanlış verilen cevap değildir. Kavram yanılgıları birer hatadır ama bütün hatalar birer kavram yanılgısı değildir (Eryılmaz, 2002). Buradan hareketle kavram yanılgısı sistemli bir biçimde hata üreten algı biçimi (Smith, diSessa, \& Roschelle, 1993) olarak da tarif edilebilir ki bu da önceki tanımda belirtildiği gibi öğrenci algısının uzman algısından uzaklaştığına işaret etmektedir. Kavram yanılgısı, zihinde bir kavramın yerine oturan fakat bilimsel olarak o kavramın tanımından farklı olması demektir (Yenilmez \& Yaşar, 2008).

İlköğretim düzeyinde özellikle öğrencilerin geometrik cisimler hakkında sahip oldukları kavramsal bilgileri analiz eden çalışmalara ülkemizde pek rastlanmadığ görülmektedir. Bu çalışmayla, geometrik kavramlar içerisinde önemli yerleri olan küp, kare ve dikdörtgenler prizmasına yönelik öğrencilerin kavram bilgilerinin ve varsa bu kavramlara yönelik yanılgılarının neler olduğunu belirlemek amaçlanmıştır.

\section{Yöntem}

Çalışma, nitel bir doğaya sahip olup bir durum çalışmasıdır. Durum çalışmasının en belirgin özelliği, güncel bir olgu, olay, durum, birey ve gruplar üzerinde odaklanılıp derinlemesine incelemeler yapılmasıdır (Fraenkel \& Wallen, 2000; Stake, 1995).

\section{Katılımcilar}

Çalışmada yer alan katılımcıların seçiminde iki türlü örnekleme seçimine gidilmiştir. Çalışma ilk olarak, ilköğretim altıncı sınıfa devam eden toplam 272 ilköğretim öğrencisi ile gerçekleştirilmiştir. Bu örnekleme seçiminde basit rastgele örnekleme yöntemi benimsenmiştir (Gay, Mills, \& Airasian, 2006). Öğrencilerin seçiminde okulun sosyo-ekonomik düzeyinin orta olmasına dikkat edilmiştir. İkinci örnekleme kapsamında yer alan katılımcıların seçiminde ise amaçsal örnekleme tekniği benimsenmiştir. $\mathrm{Bu}$ öğrenciler arasından belli ölçütleri sağlayan 12 öğrenci ile de 
görüşmeler yapılmıştır. $\mathrm{Bu}$ öğrencilerin belirlenmesinde amaçlı örnekleme yöntemlerinden ölçüt örnekleme yöntemi benimsenmiştir (Patton, 1990). Bu çalışmada ölçüt olarak kodlama anahtarında yer alan her bir koda dahil öğrenciler seçilmiştir.

\section{Veri Toplama Aracı}

Bu çalışmada veri toplamak için, araştırmacılar tarafından üç sorudan oluşan bir teşhis tanı testi (EK-1) geliştirilmiştir. Teşhis tanı testinde küp, kare prizma ve dikdörtgenler prizmasının resimleri verilmiş ve öğrencilere bu resimlerin çağrıştırdığ 1 geometrik cisimlerin isimlerini ve özelliklerini karşılarına yazmaları istenmiştir. Açık uçlu sorular sorularak öğrencilerin konuyla ilgili kavram yanılgılarının öğrenilebileceği belirtilmektedir (Doğan ve diğerleri, 2012). Daha sonra bu öğrenciler arasından belli ölçütleri sağlayan öğrencilerle de görüşmeler yapılmıştır.

\section{Veri Analizi}

Araştırmada öğrencilere sorulan teşhis testinden elde edilen verilerin analizinde hem nitel hem nicel veri analiz yöntemleri kullanılmıştır. Nicel analiz boyutunda veriler, çalışmanın başında araştırmacılar tarafından geliştirilen kodlama anahtarına göre kodlanmıştır. Bu kodlamada küp, dikdörtgenler ve kare prizma kavramlarının isimlerini, bu kavramların ortak özellikleri (Şimşek, 2006) kapsamında ele alınabilecek köşe, ayrıt ve yüz sayılarını doğru bilme ya da bilmemeleri dikkate alınmıştır. Prizmaların isimleri bir kategori ve her bir prizmaya yönelik öğrencilerin söyledikleri de alt kategoriler olarak belirlenmiştir. Alt kategoriler ise şöyledir: Geometrik cismin ismini doğru söyleme, geometrik cismin ismini ve özelliklerini doğru söyleme, geometrik şekle benzetme, resmin gerçek ismini söyleme ve yanıt verememedir. Daha sonra verilerin nicel analizi boyutunda ise öğrencilerin yanıtlarının kodlanmış biçimlerinin frekans (f) ve yüzde (\%) değerleri hesaplanmıştır.

Nitel analiz sırasında öğrencilerle yapılan görüşmeler içerik analizi ile incelenmiştir. Veriler ilk olarak kodlanmış, daha sonra temalar oluşturulmuş, verilerin kodlara ve temalara göre düzenlenmesi ve tanımlanması yapılmış ve bulgular yorumlanmıştır (Yıldırım \& Şimşek, 2005). Temalar ve kodlar arasındaki ilişkiler tablolar halinde görsel olarak sunulmuş olup bulguların yorumlanmasında da öğrencilerle yapılan görüşmelerden alıntılar yapılarak bulguların desteklenilmesi yoluna gidilmiştir. Veri analizinde araştırmacılar kodlama listesini birlikte oluşturmuş, ancak verileri ayrı ayrı kodlamışlardır. Kodlayıcılar arası güvenirlik çalışması yapılmış olup güvenirlik için her iki araştırmacı tarafından yapılan kodlamalar üzerinde Güvenirlik= Görüş Birliği/ [Görüş Birliği + Görüş Ayrılığı] X 100 formülü (Miles \& Huberman, 1994) uygulanmıştır. İki kodlayıcı arasındaki uyuşum yüzdesi \% 90 olarak hesaplanmıştir.

\section{Bulgular}

İlköğretim altıncı sınıf öğrencilerinin küp, kare ve dikdörtgenler prizmasına yönelik kavram bilgilerinin analizi sonucunda ortaya çıkan kategori ve alt kategoriler ile bunlara yönelik frekans ve yüzde dağılımı Tablo 1'de verilmiştir. 


\section{Tablo 1}

İlköğretim Öğrencilerinin Bazı Geometrik Cisimlere Yönelik Sahip Oldukları Kavram Bilgilerinin Analizi

\begin{tabular}{|c|c|c|c|}
\hline & Kategori ve Alt Kategoriler & $f$ & $\%$ \\
\hline & Geometrik cismin ismini doğru söyleme & 226 & 83 \\
\hline \multirow[t]{9}{*}{ Küp } & Geometrik cismin özelliklerini tam doğru söyleme & 20 & 7 \\
\hline & Geometrik cismin özelliklerini kısmen doğru söyleme & 62 & 23 \\
\hline & Yüz & 25 & 9 \\
\hline & Köşe & 42 & 15 \\
\hline & Ayrit & 13 & 5 \\
\hline & \multicolumn{3}{|l|}{ Yanılgilar } \\
\hline & İki boyutlu bir şekle benzetme & 17 & 6 \\
\hline & Resmin gerçek ismini söyleme & 10 & 4 \\
\hline & Yanit verememe & 15 & 6 \\
\hline \multirow[t]{10}{*}{ Kare prizma } & Geometrik cismin ismini doğru söyleme & 130 & 48 \\
\hline & Geometrik cismin özelliklerini tam doğru söyleme & 17 & 6 \\
\hline & Geometrik cismin özelliklerini kısmen doğru söyleme & 38 & 14 \\
\hline & Yüz & 20 & 7 \\
\hline & Köşe & 33 & 12 \\
\hline & Ayrit & 6 & 2 \\
\hline & \multicolumn{3}{|l|}{ Yanılgılar } \\
\hline & İki boyutlu bir şekle benzetme & 81 & 30 \\
\hline & Resmin gerçek ismini söyleme & 11 & 4 \\
\hline & Yanit verememe & 37 & 14 \\
\hline \multirow{10}{*}{$\begin{array}{l}\text { Dikdörtgenler } \\
\text { prizması }\end{array}$} & Geometrik cismin ismini doğru söyleme & 128 & 47 \\
\hline & Geometrik cismin özelliklerini tam doğru söyleme & 15 & 6 \\
\hline & Geometrik cismin özelliklerini kısmen doğru söyleme & 35 & 13 \\
\hline & Yüz & 16 & 6 \\
\hline & Köşe & 24 & 9 \\
\hline & Ayrit & 4 & 1 \\
\hline & \multicolumn{3}{|l|}{ Yanılgilar } \\
\hline & İki boyutlu bir şekle benzetme & 95 & 35 \\
\hline & Resmin gerçek ismini söyleme & 17 & 6 \\
\hline & Yanit verememe & 33 & 12 \\
\hline
\end{tabular}




\section{İlköğretim Öğrencilerinin Küp Kavram Bilgilerinin Analizine Yönelik Bulgular}

Tablo 1'de görüldüğü gibi, ilköğretim altıncı sınıf öğrencilerinin küp kavramına yönelik bilgilerinin analizine bakıldığında öğrencilerin \%83'ü küpün ismini ve \%7’si küpün özelliklerini tam doğru, \%23'ü küpün özelliklerini kısmen doğru ifade etmişlerdir. Küpün özelliklerini kısmen doğru söyleyen öğrencilerin \%9’u yüz, \%15’i köşe ve \%5'i ayrıt özelliklerinden bahsetmişlerdir. Öğrenciler ağırlıklı olarak küpün ismini doğru söylerlerken çok azı özelliklerini tam doğru söyleyebilmiştir. Küpün ismini ve özelliklerini aynı anda doğru söyleyen öğrencilerin azlığı dikkat çekici bir durumdur.

Öğrencilerin bazılarının küp kavramının ismini ve özelliklerini doğru söylerken birtakım sorunları olduğu da görülmüştür. Öğrencilerin \%6'sı küp resmini iki boyutlu geometrik şekle (kare) benzetirken, \%4'ü resmin gerçek ismini söylemiş (kutu) ve $\%$ 6'sı da yanıt verememiştir.

\section{İlköğretim Öğrencilerinin Kare Prizma Kavram Bilgilerinin Analizine Yönelik Bulgular}

Tablo 1'de görüldüğü gibi, ilköğretim altıncı sınıf öğrencilerinin kare prizma kavramına yönelik bilgilerinin analizine bakıldığında öğrencilerin \%48'i kare prizmanın ismini ve \%6's1 kare prizmanın özelliklerini tam doğru, \%14'ü kare prizmanın özelliklerini kısmen doğru ifade etmişlerdir. Kare prizmanın özelliklerini kısmen doğru söyleyen öğrencilerin \%7'si yüz, \%12'si köşe ve \%2'si ayrıt özelliklerinden bahsetmişlerdir. Öğrenciler ağırlıklı olarak kare prizmanın ismini doğru olarak söylerlerken çok azı özelliklerini tam doğru söyleyebilmiştir. Küp kavramına yönelik bilgilerin analizinde olduğu gibi kare prizmanın ismini ve özelliklerini aynı anda doğru söyleyen öğrencilerin yüzdesinin az olduğu göze çarpmaktadır.

Öğrencilerin bazılarının kare prizma kavramının ismini ve özelliklerini doğru söylerken birtakım sorunları olduğu görülmüştür. Öğrencilerin \%30’u kare prizmanın resmini iki boyutlu geometrik şekle benzetirken, \%4'ü resmin gerçek ismini söylemiş ve $\% 14$ 'ü de yanıt verememiştir.

\section{İlköğretim Öğrencilerinin Dikdörtgenler Prizması Kavram Bilgilerinin Analizine Yönelik Bulgular}

Tablo 1'de görüldüğü gibi, ilköğretim altıncı sınıf öğrencilerinin dikdörtgenler prizması kavramına yönelik bilgilerinin analizine bakıldığında, öğrencilerinin \%47’si dikdörtgenler prizmasının ismini ve \%6'sı dikdörtgenler prizmasının özelliklerini tam doğru, \%13'ü de dikdörtgenler prizmasının özelliklerini kısmen doğru ifade etmişlerdir. Dikdörtgenler prizmasının özelliklerini kısmen doğru söyleyen öğrencilerin \%6’si yüz, \%9'u köşe ve \%1'i ayrıt özelliklerinden bahsetmişlerdir. Öğrenciler ağırlıklı olarak dikdörtgenler prizmasının ismini doğru olarak söylerlerken çok azı özelliklerini tam olarak doğru söyleyebilmiştir. Diğer geometrik cisimlerde olduğu gibi, dikdörtgenler 
prizmasının ismini ve özelliklerini doğru söyleyen öğrencilerin yüzdesinin az olduğu görülmektedir.

Öğrencilerin bazılarının dikdörtgenler prizması kavramının ismini ve özelliklerini doğru söylerken birtakım sorunları olduğu görülmüştür. Öğrencilerin \%35’i dikdörtgenler prizmasının resmini iki boyutlu geometrik şekle benzetirken, \%6's1 resmin gerçek ismini söylemiş ve \%12'si de yanıt verememiştir.

\section{Yanılgıların Açıklanması}

Öğrencilerin cisimlerin özelliklerini açıklamada problem yaşadıkları görülmüştür. Köşe sayısını yanlış hesaplayan öğrencilerin hataları, "Cisimler altı şekilden oluştuğu ve her şekilde dört köşe olduğu için toplam 24 köşe bulunmaktadır." ifadesiyle açıklanmaktadır. Ayrıca, köşe sayısı ile ayrıt sayısını karıştırmanın da hataya neden olduğu belirlenmiştir. Benzer durum ayrıt özelliklerini yanlış yapan öğrencilerde de görülmektedir.

Öğrencilerin yüz özellikleri hakkındaki hatalarının yüz sayısı ile ilgili yanılgılarından (Kare prizma beş yüzlüdür), yüz ile boyut kavramlarını birbirine karıştırmalarından (Küp üç yüzlüdür. Uzunluk, genişlik ve derinlik) ve cismi oluşturan yüzlerin özelliklerini tam olarak kavrayamamalarından (Kare prizma üç kare ve üç dikdörtgenden oluşur. Dikdörtgenler prizmasında bütün dikdörtgenler eşittir) kaynaklandığı görülmüştür.

Öğrencilerle yapılan görüşmeler sonucunda katı cisimleri iki boyutlu şekillere benzetmeye neden olan faktörün, öğrencilerin cisimlerin resimlerini bir bütün olarak değil de parça olarak değerlendirmeleri olduğu belirlenmiştir. Bir öğrenci "Bu (küp gösterimini belirterek) bir kare çünkü bütün kenarları birbirine eşit" yorumunu yapmıştır. Yine başka bir öğrenci dikdörtgenler prizmasını benzer bir açıklamayla dikdörtgen olarak nitelendirmiştir. Kare prizmayı kareye veya dikdörtgene benzeten ve aslında kararından emin olamayan öğrencilerden biri, "Bu kareye benziyor ama dikdörtgen de olabilir çünkü buralar (dikdörtgenleri göstererek) dikdörtgen gibi duruyor.” şeklinde bir açıklama yapmıştır.

Öğrencilerin katı cisimlerin gerçek isimlerini söylemelerinin nedenleri arasında öğrencilerin gerçek hayatta karsılaştıkları nesnelerin derste öğrendikleri kavramlara baskın gelmesi sayılabilir. Resimdeki cismin gerçek ismini söyleyen öğrencilerin biriyle yapılan görüşme aşağıdaki biçimdedir:

- Bu kutu babamin saat kutusuna benziyor?

- Peki, bu kutu hangi cisme benziyor?

- Bilmem.

- Hangi cisimleri biliyorsun?

- Prizma, küp.

- Peki, küp nasıl bir cisimdir?

- Karelerden oluşur? Aynı bu saat kutusu gibi.

de bu sonucu destekler niteliktedir. 
Cevap vermeyenlerden elde edilen görüşme sonuçları bu öğrencilerde bilgi eksikliğinin olduğuna veya sorudaki cismin algılanmasında bir sorun olduğuna işaret etmektedir. Bu duruma yönelik görüşme örneği aşağıdaki biçimdedir:

- Hangi geometrik cisimleri biliyorsun?

- Kare, dikdörtgen, küp.

- Küpün özellikleri nelerdir?

- Küp karelerden oluşur.

- Peki, bu şekilde de kareler var. Bu da küp olabilir mi?

- Ama burada üç kare var. Küpte altı kare olması lazım.

Öğrencinin burada verdiği cevaplardan öğrencinin küpün özelliklerini aslında bildiği anlaşılsa da soruda üç yüzü görünen ve küpe benzeyen şekli, üç kareden oluşan bir şekil gibi yorumlaması öğrencinin mekan/uzay algısında bir sorun olduğunu göstermektedir.

\section{Sonuç ve Tartışma}

$\mathrm{Bu}$ çalışmada altıncı sınıf öğrencilerininin küp, kare prizma ve dikdörtgenler prizmasının temsilleri ve geometrik özellikleri hakkındaki bilgileri analiz edilmiştir. Çalışmanın sonuçları katılan öğrencilerin sınıfı ve sayısıyla, ele alınan cisimlerle ve kullanılan veri toplama aracıyla sınırlıdır.

İlköğretim öğrencilerinin küp, kare ve dikdörtgenler prizması kavramlarına yönelik bilgileri analiz edildiğinde, geometrik cismin ismini ve özelliklerini aynı anda belirten öğrencilerin yüzdesinin düşük olduğu göze çarpmaktadır. Geometrik cisimler arasında öğrencilerin en fazla küpün ismini doğru bildikleri, kare prizma ve dikdörtgenler prizmasının ismini doğru bilme yüzdesinin ise düşük olduğu dikkati çekmektedir. Öğrencilerin, köşe sayılarına kıyasla, köşe özelliklerini bilirken daha başarılı olmaları, öğrencilerin köşe sayısının değişebileceği ile ilgili algısal yanılgılarının olduğunu göstermesi açısından ilginç bir sonuçtur. Benzer durum ile ayrıt özelliklerinin belirlenmesinde de karşılaşılmıştır. Bununla birlikte, öğrencilerin yüz sayılarının ve özelliklerinin belirlenmesine yönelik kavram bilgisi eksikliklerine sahip oldukları belirlenmiştir. Altıncı sınıf öğrencileriyle yapılan bir çalışmada, Kurtuluş ve Yolcu (2013), öğrencilerin birim küplerle oluşturulan yapılardaki birim küp sayılarını, yüz sayılarını ve yapıların değişik açılardan görünümlerini belirlemede zorlandıklarını ortaya koymuşlardır. Yine bu çalışma, öğrencilerin köşe, yüz ve ayrıt gibi kavramları belirlemede zorlandıklarını göstermektedir. Öğrencilerde bulunan bu yanılgılar, katı cisimlerin öğretimi yapılırken cisimler arasında karşılaştırmalara yer verilmesi ve modeller üzerinden uygulama yaptırılarak öğrencilere keşfettirilmesi ile giderilebilir.

Matematiğin yığglmalı yapısı nedeniyle; bir önceki bilgiler ve kavramlar, bir sonrakiler için bir basamak oluşturduğundan; öğrencilere matematik kavram bilgilerinin tam olarak verilmesi, kavram yanılgılarının ve bilgi eksikliğinin belirlenmesi, bu yanılg1 ve eksikliklerinin giderilmesi için çözüm yolları aranmalıdır (Küçük \& Demir, 2009). Kavram bilgisinin tam olarak kazandırılabilmesi için konu ile ilgili tanımların, 
özelliklerin eksiksiz ve doğru olarak verilmesi gerektiği ifade edilmektedir (Küçük \& Demir, 2009).

İlköğretim öğrencilerinin küp, kare ve dikdörtgenler prizmasına yönelik birtakım kavram yanılgılarının da olduğu bu araştırmayla ortaya çıkan bir başka sonuçtur. $\mathrm{Bu}$ kavram yanılgılarının neler olduğuna bakıldığında, her bir geometrik cisme yönelik kavram bilgilerinin analizinde ortaya çıkan yanılgıların ortak olduğu görülmüştür. Bunlar; geometrik cismi iki boyutlu geometrik şekle benzetme ve resmin gerçek ismini söylemedir. Bunun yanı sıra, yanıt verememe durumlarının da yaşandığı görülmüştür. Oberdorf ve Taylor-Cox (1999) yine öğrencilerin geometrik cisimleri, bu cisimlerin yüzlerini oluşturan şekillerle adlandırmalarına işaret etmiş ve kitaplarda da bu durumun göz ardı edildiğini belirtmişstir.

Öğrencilerde var olan kavram yanılgılarını değiştirmenin zorlu bir süreç olduğu (Yenilmez \& Yaşa, 2008) düşüldüğünde öğretmenler, öğrencilerin derse karş1 motivasyonlarını artırmalı, bilginin kalıcı ve etkin öğrenilmesini engelleyen kavram yanılgılarının oluşmamasına özen göstermelidirler (Doğan ve diğerleri, 2012). Yine bu doğrultuda, geometri konularındaki kavram yanılgılarını ortadan kaldırma aşamaları arasında (1) kavramların karakteristik özelliklerine vurgu yapılması, (2) öğrencilerin bir kavrama (cisme) örnek olmayan temsilleri belirlemede zorlandığı durumlarda bol miktarda örnek olan ve olmayan temsillerin kullanılması, (3) kullanılan dile dikkat edilmesi ve (4) anlamanın sorgulanması ve genellemelerin yaygınlaştırlıması sayilmaktadır (Oberdorf \& Taylor-Cox, 1999).

Öğrencilerin geometrik cisimlere yönelik kavramsal bilgilerinin geliştirilmesi için farklı etkinlikler yapılabilir. Geogebra gibi dinamik yazılımlar, bu konuların öğretimi sırasında kullanılarak öğrencilerin katı cisimlerin özelliklerini ve aralarındaki ilişkileri keşfetmeleri sağlanabilir. Öğrencilerdeki kavram yanılgılarını ortadan kaldırmaya yardımcı kavramsal değişim metinleri ile prizmalara yönelik kavram yanılgılarının giderilip giderilmediğine bakılabilir.

\section{Kaynakça}

Altun, M. (1999). Geometri öğretimi. A. Özdaş (Ed.) içinde, Anadolu Üniversitesi Açık Öğretim Fakültesi Illkögretim Öğretmenliği Lisans Tamamlama Programı: Matematik ĕ̌itimi (ss. 160-186). Eskişehir: Anadolu Üniversitesi Yayınları.

Altun, M. (2008). Illköğretim ikinci kademe (6, 7 ve 8. sınıflarda) matematik öğretimi (6. bask1). Ankara: Aktüel.

Battista, M. T., \& Clements, D. H. (1998). Finding the number of cubes in rectangular cube buildings. Teaching Children Mathematics, 4, 258-264.

Ben-Chaim, D., Lappan, G., \& Houang, R. T. (1985). Visualizing rectangular solids made of small cubes: Analyzing and effecting students’ performance. Educational Studies in Mathematics, 16, 389-409.

Bourgeois, R. D. (1986). Third graders' ability to associate foldout shapes with polyhedra. Journal for Research in Mathematics Education, 17(3), 222-230. 
Dağlı, H., \& Peker, M. (2012). İlköğretim 5. sınıf öğrencileri geometrik şekillerin çevre uzunluğu hesaplamaya ilişkin ne biliyor? Kuramsal Ĕ̆itimbilim Dergisi, 5(3), 330351. http://www.keg.aku.edu.tr adresinden alınmıştır.

Despina, A. S., Leikin, R., \& Silver, E, A. (1999). Exploring students' solution strategies in solving a spatial visualization problem involving nets. In O. Zaslavsky (Ed.), Proceedings of the 23rd conference of the international group for the psychology of mathematics education (Vol. 4, pp. 241-248). Haifa, Israel.

Doğan, A., Özkan, K., Çakır, N. K., Baysal, D., \& Gün P. (2012). İlköğretim ikinci kademe öğrencilerinin yamuk kavramına ait yanılgıları ve bu yanılgıların sınıf seviyelerine göre değişimi. Uşak Üniversitesi Sosyal Bilimler Dergisi, 5(1), 104116.

Eryılmaz, A., \& Sürmeli, E. (2002). Üç-aşamalı sorularla öğrencilerin ısı ve sicaklık konularındaki kavram yanılgılarının ölçülmesi. V. Ulusal Fen ve Matematik Eğitimi Kongresinde sunulmuş sözlü bildiri, Orta Doğu Teknik Üniversitesi, Ankara, Türkiye.

Fraenkel, J. R., \& Wallen, N. E. (2000). How to design and evaluate research in education. NY: McGraw-Hill.

Gay, L. R., Mills, G. E., \& Airasian, P. (2006). Educational research: Competencies for analysis and applications (8th ed.). NJ: Pearson Prentice Hall.

Gutiérrez, A., Jaime, A., \& Fortuny, J. M. (1991). An alternative paradigm to evaluate the acquisition of the van Hiele levels. Journal for Research in Mathematics Education, 22(3), 237-251.

Kaplan, A., İşleyen, T., \& Öztürk, M. (2011). 6. sınıf oran orantı konusundaki kavram yanılgıları. Kastamonu Eğitim Dergisi, 19(3), 953-968.

Kar, T., Çiltaş, A., \& Işık, A. (2011). Cebirdeki kavramlara yönelik öğrenme güçlükleri üzerine bir çalışma. Kastamonu Eğitim Dergisi, 19(3), 939-952.

Kurtuluş, A., \& Yolcu, B. (2013). A study on sixth-grade Turkish students' spatial visualization ability. The Mathematics Educator, 22(2), 82-117.

Küçük, A., \& Demir, B. (2009). İlköğretim 6-8. sınıflarda matematik öğretiminde karşılaşılan bazı kavram yanılgıları üzerine bir çalışma. Dicle Üniversitesi Ziya Gökalp Ĕ̈itim Fakültesi Dergisi, 13, 97-112.

Lawrie, C., Pegg, J., \& Gutiérrez, A. (2000). Coding the nature of thinking displayed responses on nets of solids. In T. Nakahara \& M. Koyama (Eds.), Proceedings of the 24th Conference of the international group for the psychology of mathematics education (Vol. 3, pp. 215-222). Hiroshima, Japan.

Lehrer, R., Jenkins, M., \& Osana, H. (1998). Longitudinal study of children’s reasoning about space and geometry. In R. Lehrer \& D. Chazan (Eds.), Designing learning environments for developing understanding of geometry and space (pp. 137-167). Mahwah, NJ: Erlbaum. 
Markopoulos, C., \& Potari, D. (2003). Using dynamic transformations of solids to promote children's geometric reasoning. Proceedings of CERME4, cilt(say1), sayfa numaraları. $\quad$ Retrieved from http://www.cerme4.crmes/Papers\%20definitions/7/markopoulos.pdf

McClintock, E., Jiang, Z., \& July, R. (2002). Students' development of threedimensional visualization in the Geometer's Sketchpad environment. Retrieved from ERIC database. (ED471759).

Miles, M. B., \& Huberman, M. A. (1994). An expanded sourcebook: Qualitative data analysis. London: Sage.

Milli Eğitim Bakanlığı. (2009). Illköğretim matematik dersi 1-5.sınıflar öğretim programi. Ankara: Devlet Kitapları Basımevi.

Murphy, G. L. (2002). The big book of concepts. USA: Massachusetts Institute Technology.

Oberdorf, C., \& Taylor-Cox, J. (1999). Shape up. Teaching Children Mathematics, 5(6), 340-345.

Patton, M. Q. (1990). Qualitative evaluation and research methods (2nd ed.). CA: Sage Publication.

Pesen, C. (2007). Öğrencilerin kesirlerle ilgili kavram yanılgıları. Eğitim ve Bilim, 32(143), 79-88.

Potari, D., \& Spiliotopoulou, V. (1992). Children's representation of the development of solids. For the Learning of Mathematics, 12(1), 38-46.

Saads, S., \& Davis, G. (1997). Spatial abilities, van Hiele levels and language use in three dimensional geometry. In E. Pehkonen (Ed.), Proceedings of the 21st Conference of the international group for the psychology of mathematics education (Vol. 4, pp. 104-111). Lahti, Finland.

Smith, J. P., diSessa, A. A., \& Roscheile, J. (1993). Misconceptions reconceived: A constructivist analysis of knov/ledge in transition. The Journal of the Learning Sciences, 3(2), 115-163.

Stake, R. E. (1994). Case studies. In Y. K. Denzin \& Y. S. Lincoln (Eds.), Handbook of qualitative research (pp. 236-246). Thousand Oaks, CA: Sage.

Şimşek, A. (2006). Kavramların öğretimi. A. Şimşek (Ed.) içinde, Iç̧erik türlerine dayalı öğretim (ss. 27-71). Ankara: Nobel Yayın Dağıtım.

Ülgen, G. (2001). Kavram geliştirme: Kuramlar ve uygulamalar (3. bask1). Ankara: PegemA Yayınları.

Yenilmez, K., \& Yaşa, E. (2008). İlköğretim öğrencilerinin geometrideki kavram yanılgıları. Uludă̆ Üniversitesi Eğitim Fakültesi Dergisi, cilt(sayı), 461-483.

Yıldırım, A., \& Şimşek, H. (2005). Sosyal bilimlerde nitel araştırma yöntemleri. (Genişletilmiş 5. baskı). Ankara: Seçkin Yayınları. 
Y1lmaz, Z., \& Yenilmez, K. (2008). İlköğretim 7. ve 8. sınıf öğrencilerinin ondalık sayılar konusundaki kavram yanılgıları (Uşak ili örneği). Afyon Kocatepe Üniversitesi Fen Bilimleri Dergisi, 8(1), 291-312. 


\section{Ek-1}

\section{Teşhis Tanı Testi}

AD:

SOYAD:

SINIF:

Aşağıda geometrik cisimlerin bazıları ile ilgili toplam üç soru bulunmaktadır. Bu soruları dikkatlice okuyup yanıtlayınız. Başarılar dileriz.

1) Aşağıdaki resmin çağrıştırdığı geometrik cismin ismini ve bu cismin bildiğiniz özelliklerini karşısına yazınız.

2) Aşağıdaki resmin çağrıştırdığı geometrik cismin ismini ve bu cismin bildiğiniz özelliklerini karşısına yazınız.

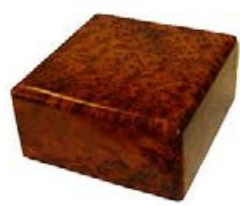

3) Aşağıdaki resmin çağrıştırdığı geometrik cismin ismini ve bu cismin bildiğiniz özelliklerini karşısına yazınız.

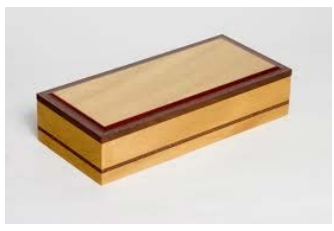

